\title{
EVALUATION OF THE DYNAMIC MODELING AND DISCHARGE PERFORMANCE OF A MAGNESIUM BATTERY ACTIVATED BY SEAWATER
}

\author{
Supriyono $^{1 *}$ \\ ${ }^{1}$ Department of Chemical Engineering, Faculty of Engineering, Universitas Brawijaya, \\ Jl. MT. Haryono No. 167, Malang 65145, Indonesia
}

(Received: January 2018 / Revised: February 2018 / Accepted: April 2018)

\begin{abstract}
This study focuses on an evaluation of the dynamic modeling and discharge performance of magnesium battery activated by sea water. Modeling is important to determine the optimum condition of battery discharge operation. The modeling was performed by modifying the Shepherd model approach by combining an $R_{\text {int }}$ equivalent circuit model to avoid the looping algorithm problem. Initial parameters were obtained from battery discharge manufacturing data on open operating systems. The battery anode used magnesium foil, the cathode used carbon, while the electrolyte used $3.5 \%$ wt $\mathrm{NaCl}$ solution. The battery discharge test to obtain manufacturing data was carried out with variations in current loads of $0.01 \mathrm{C}, 0.05 \mathrm{C}$ and $0.1 \mathrm{C}$ until the potential and current were zero. Battery discharge performance evaluation can also be performed from manufacturing data analysis. Potential battery discharge decreased from \pm 1.49 $\mathrm{V}$ to $\pm 1.30 \mathrm{~V}$, while the battery discharge potential was relatively stable at $\pm 1.30 \mathrm{~V}$ to the $\mathrm{SOC}_{\min }$ potential value $( \pm 1.29 \mathrm{~V})$. It can be seen from the different values of exponential and nominal potential that the parameters were not too significant. The modeling has convergence on the discharge parameters, such as $E_{0}=1.303 \mathrm{~V} ; R=0.012 \Omega ; K_{d r}=0.01 \Omega ; K_{d v}=5.794 \times 10^{-4}$ V/A.h $A=0.195 \mathrm{~V}$; and $B=140$ (A.h) ${ }^{-1}$. The $\mathrm{SOC}_{\min }$ value of $5 \%$ indicates a minimum limit of battery operation that is permitted for battery performance to drop suddenly. The $\mathrm{SOC}_{\max }$ value of $93 \%$ indicates the maximum allowable limit for the battery to operate stably. The percentage of simulated data error compared to the manufacturing data is $0.85 \%$.
\end{abstract}

Keywords: Dynamic modeling; Magnesium battery; Seawater; Shepherd's modification model

\section{INTRODUCTION}

Magnesium batteries activated by seawater are a renewable energy source (Chen et al., 2013). Magnesium can replace conventional seawater battery anodes ( $\mathrm{Zn}, \mathrm{Al}, \mathrm{Sn}$ ) because it has a discharge profile that meets the criteria for potential, current and discharge energy, and even has a discharge potential greater than conventional seawater batteries (Supriyono et al., 2017). Magnesium is also worthy of consideration for use as a seawater battery theoretically. It has a standard reduction potential value of $-2.370 \mathrm{~V}$ compared to a Standard Hydrogen Electrode (SHE), which is high enough for the battery anode (Bard \& Faulkner, 2001). Magnesium can store large amounts of power with a small mass and material volume. It has a high gravimetric charge density theoretical value of $2233 \mathrm{mAh} / \mathrm{gram}$ and a high volumetric charge density theoretical value of $3881 \mathrm{mAh} / \mathrm{cm}^{3}$. Magnesium is very abundant in the earth's crust and moreover the preparation of magnesium battery activated by seawater is also relatively easy

*Corresponding author's email: supriyono16@ub.ac.id, Tel. +62-341-587710, Fax. +62-341-574140

Permalink/DOI: https://dx.doi.org/10.14716/ijtech.v9i4.1362 
(Koontz \& Lucero, 2002).

One application of magnesium batteries activated by seawater is an energy source for lighting buoy lamps, in which the battery electrode is dyed directly in the open sea water system. Magnesium has a galvanostatic discharge pattern similar to that of lithium, but differs in its potential value range, current, capacity and discharge energy. The modeling of a magnesium battery activated by seawater requires prediction of the optimum conditions and the possibility to control these as an energy source for lighting buoy lamps effectively and efficiently. Dynamic modeling for lithium batteries is widely discussed in the literature ( $\mathrm{Li} \& \mathrm{Ke}, 2011$; He et al., 2012; Zhao et al., 2015; Guo et al., 2017; Benabdelaziz et al., 2017). However, modeling of magnesium batteries activated by seawater has not been widely discussed because it is a new energy material that has not been exploited optimally. The experimental method used to find the optimum conditions for battery operation takes a long time and is expensive. Simulations require a relatively shorter time at a lower cost to determine the optimum operating conditions of magnesium batteries activated by seawater. Battery modeling is important to recognize more detailed battery characteristics, such as the minimum and maximum limit conditions of the allowed State of Charge (SOC) batteries. By knowing the SOC boundary conditions, the battery can be set to safe operation.

The basic model approach of electrical circuits is widely used in presenting battery characteristics. The simplest basic equivalent circuit model consists of an ideal potential source arranged in series with the internal resistance. This is also called the $R_{\text {int }}$ equivalent circuit model (Durr et al., 2006). The basic model of this circuit is very simple, but it is less able to represent battery SOC conditions. Another basic equivalent circuit model is based on a series of open potentials arranged in series, with resistors connected to a series of capacitor-resistor parallel systems called the Warburg impedance (Kuhn et al., 2006). The identification of the parameters in a model is called impedance spectroscopy (Mauracher et al., 1997). Shepherd's modification model is an equation to describe the electrochemical parameters of the battery on the terminal electric potential, open circuit potential, discharge current, internal resistance, and SOC (Shepherd et al., 1965). The Shepherd model is relatively important, but causes looping algorithm problems in closed loop on modular models. A differential equation which represents the capacitor in the Shepherd modification model requires a longer simulation time. This looping algorithm problem can be solved by assuming the battery equivalent circuit model into $R_{\text {int }}$ (Tremblay et al., 2007).

In this study, the modeling used is the Shepherd modification model, combining the equation with the $R_{\text {int }}$ equivalent circuit model on the discharge process of the magnesium battery activated by seawater. In the $R_{\text {int }}$ equivalent circuit model, the differential equations that present the capacitor are removed to prevent long looping time problems. Some initial parameters use manufacturing data from the discharge curve of the magnesium battery in an open environment system, from which the discharge characteristics can also be studied. The discharge curve based on manufacturing data is also used to validate the model obtained.

\section{METHODS}

\subsection{Battery Simulation Models}

\subsubsection{Shepherd's battery simulation model}

Shepherd's battery simulation model is very popular, and is applied to battery modeling in electric vehicles that have complex variables due to the influence of deceleration and acceleration. The operating conditions of magnesium batteries activated by seawater also have similarities with the model of an electric vehicle battery, in the form of seawater that continually moves dynamically. This dynamic movement of seawater makes the concentration 
of $\mathrm{NaCl}$ in the seawater also change dynamically. The equivalent circuit model for potential and current describes how the terminal potential of the battery changes with time. This simulation model uses the Shepherd model for constant discharge current, as shown in Equation 1:

$$
V_{b a t t}(t)=E_{0}-K_{d v} \cdot \frac{Q}{Q-i . t} \cdot i(t)-R_{0} \cdot i(t)
$$

where $E_{0}$ is the battery constant potential (V unit); $K_{d v}$ is the polarization potential constant (V/A.h unit); $Q$ is the battery full capacity (A.h unit); $V_{\text {batt }}(t)$ is the battery terminal potential to the time change (V unit); i.t is the discharge capacity to the time change (A.h unit); and $i(t)$ is the dynamic current to the time change (A unit).

The battery discharge parameters can be derived from the Shepherd model (Li \& Ke, 2011). The ideal battery discharge curve is shown in Figure 1, where $Q_{\text {full }}$ is battery capacity at full condition (A.h unit); $Q_{n o m}$ is battery capacity at the end of nominal zone condition (A.h unit); $Q_{\text {exp }}$ is battery capacity at the end of exponential zone condition (A.h unit); $V_{\text {full }}$ is battery discharge potential at full condition ( $\mathrm{V}$ unit); $V_{\text {nom }}$ is battery discharge potential at the end of nominal zone condition (A.h unit); and $V_{\text {exp }}$ is battery discharge potential at the end of exponential zone condition (A.h unit)._The parameters obtained from Figure 1 are the potential and discharge capacity, which can be used to determine the constant parameters of $K_{d r}, K_{d v}, R_{0}$, and $E_{0}$. The Shepherd modification model is a general modification model for describing the exponential battery parameters in more detail (Rao et al., 2003; Tremblay et al., 2007). This modeling is known as the Shepherd modification model (Li \& Ke, 2011). The discharge equation for the Shepherd modification model is shown in Equation 2:

$$
V_{b a t t}(t)=E 0-K_{d r} \cdot \frac{Q}{Q-i . t} \cdot\left(i^{*}\right)-K_{d v} \cdot \frac{Q}{Q-i * t} \cdot(i . t)-R_{0} \cdot i(t)+A \cdot e^{-B . i . t}
$$

where $A$ is the amplitude of the exponential zone (V unit); B is the constant inverse time in the exponential zone ((A.h $)^{-1}$ unit); $i$ is the discharge load current (A unit); $i *$ is the filtered electric current passing through the polarization resistance (A unit); $K_{d r}$ is the coefficient of the polarization resistance ( $\Omega$ unit); and $K_{d v}$ is the coefficient of the polarization overpotential (V/A.h unit).

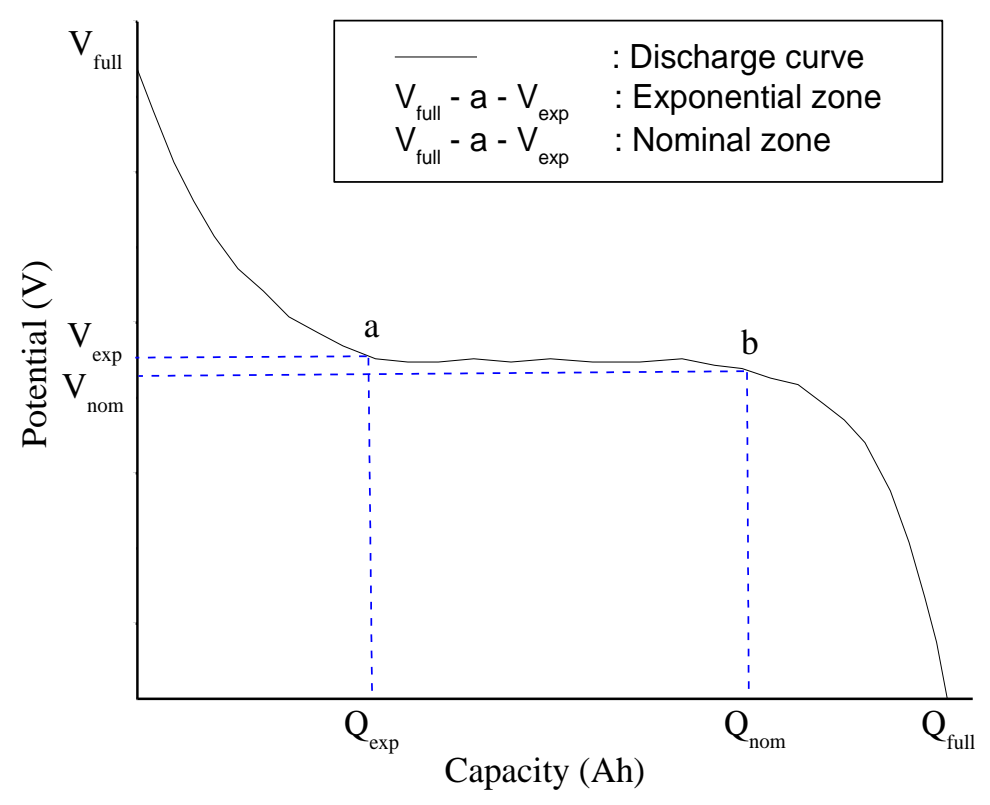

Figure 1 Ideal curve model for battery discharge 


\subsubsection{Equivalent circuit model}

The various approaches to battery modeling depend on what specifications are desired, and include the experimental approach, electrochemistry, and basic models of electrical circuits (Tremblay \& Dessaint, 2009). Equivalent circuit models are fairly simple and can represent the condition of steady state and dynamic battery parameters (Tremblay \& Dessaint, 2009). The equivalent circuit approach is widely used because of short time needed for simulation (Rao et al., 2003). In high order modeling, the optimization problem makes it difficult to obtain convergent results, even meaning an efficient solution cannot be reached.

The internal resistance equivalent circuit model $\left(R_{\text {int }}\right)$ has a constant potential value in the series arrangement with the resistor, as shown in Figure 2 (Tremblay et al., 2007). In Figure 2, $i(t)$ is the internal dynamic current of the battery (A unit); $R_{0}$ is the battery's internal resistance ( $\Omega$ unit); $V_{\text {batt }}$ is the terminal output potential of the battery (V unit); and the $V_{o c}$ is the battery input potential ( $\mathrm{V}$ unit). The terminal output potential for the $R_{\text {int }}$ model is shown in Equation 3:

$$
V_{b a t}(t)=V_{O C}-R_{0} \cdot i(t)
$$

This model does not include SOC batteries directly. However, they can be expressed as potential functions on an open circuit. Other equivalent circuits include the effect of battery polarization using a resistor-capacitor (RC) parallel circuit. Although the RC parallel circuit model is more detailed in predicting discharge parameters, the differential equations which present the capacitor lead to looping algorithm problems. In this research, an $R_{\text {int }}$ equivalent circuit model is used to avoid these problems.

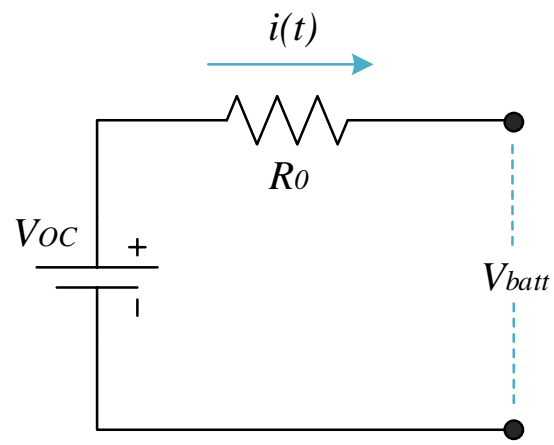

Figure $2 R_{\text {int }}$ equivalent circuit model

\subsection{Preparation of Modeling Approach}

\subsubsection{Battery manufacturing data retrieval}

\subsubsection{Tools and materials}

The analyzer used for data retrieval was a BST8 series type battery analyzer for the battery discharge test (maximum current of $3 \mathrm{~A}$; maximum potential of $5 \mathrm{~V}$ ), together with an electrochemical vessel with dimensions of $30 \mathrm{~cm}$ long, $20 \mathrm{~cm}$ wide and $20 \mathrm{~cm}$ high. The materials used for the manufacturing data retrieval were magnesium foil with a purity of $99.5 \% \mathrm{wt}$ and dimensions of $100 \mathrm{~mm}$ long, $3 \mathrm{~mm}$ wide and $0.2-0.3 \mathrm{~mm}$ thick, supplied by Merck Millipore; $\mathrm{NaCl}$ solution of a purity of 3.5\%wt, which is the average content of $\mathrm{NaCl}$ in seawater; and graphite with dimensions of $100 \mathrm{~mm}$ long, $10 \mathrm{~mm}$ wide and $5 \mathrm{~mm}$ thick.

\subsubsection{Battery manufacturing data testing}

Experiments were conducted for manufacturing data retrieval. A simple schematic is shown in Figure 3. The experiments were performed with an open system battery design, which was conducted according to the condition of the seawater battery used to power the light on the buoy. The magnesium foil was used as an anode battery or negative electrode, and the graphite was used as a battery cathode or positive electrode. $3.5 \% \mathrm{wt} \mathrm{NaCl}$ solution was used as an 
electrolyte solution. The distance between electrodes was $\pm 0.5 \mathrm{~cm}$, and the anode and cathode were immersed into an electrolyte solution with a depth of $\pm 7.5 \mathrm{~cm}$. The battery operated at room temperature $\left( \pm 23^{\circ} \mathrm{C}\right)$. The discharge was performed up to zero discharge potential by using the BST8 series type battery analyzer at $0.01 \mathrm{C}, 0.05 \mathrm{C}$ and $0.1 \mathrm{C}$ constant discharge current. The battery analyzer was connected to a computer, which recorded the battery discharge data.

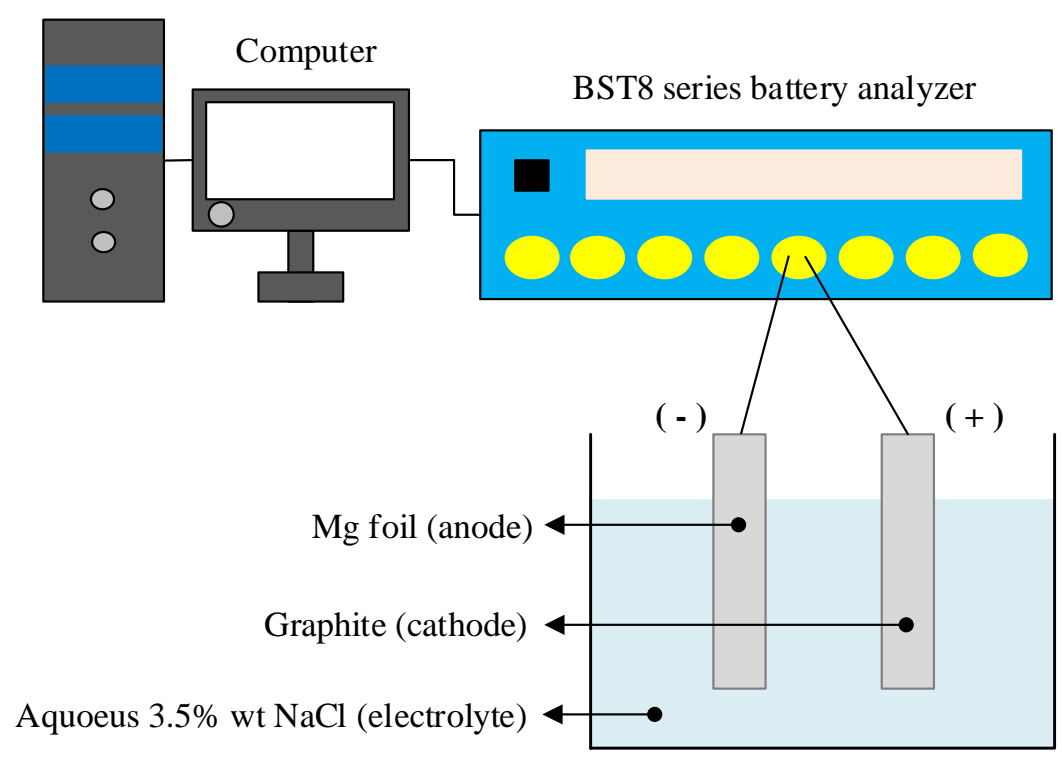

Figure 3 Simple scheme of the battery discharge performance testing with the BST8 series battery analyzer

\subsection{Proposed Modeling Approach}

Regression fittings for manufacturing data and equivalent circuits were used to present the discharge parameters of the battery. The preparation of the potential and current equations was a combination of the Shepherd model Equation 1 and the Shepherd modification model Equation 2. Parameters A and B in Equation 2 were derived from the point at the exponential zone of the ideal discharge curve shown in Figure 1.

Based on the battery discharge data obtained, battery parameters such as $V_{\text {full }}, V_{\text {exp }}, V_{\text {nom }}, Q_{\text {full }}$, $Q_{e x p}$, and $Q_{n o m}$. From the data in the form of battery discharge parameters, other parameters can be calculated to present the discharge curve of the simulation results. Examples of parameter calculations can be found below.

1. Amplitude of the potential in the exponential zone ( $A$, Volt units)

The exponential zone of the amplitude, or $A$, was calculated by Equation 4:

$$
A=V_{\text {full }}-V_{\text {exp }}
$$

2. Charge at end of exponential zone $\left(B, A \cdot h^{-1}\right.$ unit)

The charge at end of the exponential zone of the battery discharge curve, or $B$, was calculated by Equation 5:

$$
B=\frac{2.8}{Q_{\exp }}
$$

The scalar value was 2.8 to improve the fitting of the battery data.

3. Polarization overpotential coefficient ( $K_{d v}$, V/A.h unit) 
The coefficient of polarization overpotential, $K_{d v}$, was calculated with $V_{f u l l}$ and the final portion of the nominal zone of the discharge curve, as shown in Equation 6:

$$
K_{d v}=0.001 \cdot\left[V_{\text {full }}-V_{\text {nom }}+A *\left(e^{-B \cdot Q_{\text {nom }}}-1\right)\right] \cdot \frac{Q_{\text {full }}-Q_{\text {nom }}}{Q_{\text {nom }}}
$$

The scalar value was 0.001 to improved battery data fit.

4. Inner resistance $\left(R_{0}, \Omega\right.$ unit)

Battery inhibition for steady-state conditions is represented by $R$, as calculated by Equation 7 :

$$
R=V_{\text {nom }}\left(\frac{1-\eta}{\lambda \cdot Q_{\text {nom }}}\right)
$$

where $\eta$ is battery efficiency, and $\lambda$ is the loaded current used for discharge testing under steady state operating conditions.

If the resistance in the battery is assumed to be two functions, temperature and SOC, it will become an internal resistance in the battery under dynamic conditions. With the manufacturing data obtained from the discharge test of the magnesium battery activated by seawater, the linear multiple regression relationship is represented by $R_{0}$. To prevent over-fitting of data, regression fittings for order one under dynamic conditions were selected by Equation 8:

$$
R_{0}=c_{1} \cdot T+c_{2} \cdot i . t+c_{3}
$$

where $c_{1}, c_{2}$, and $c_{3}$ are constant values of multiple linear regression; $T$ is the allowed operating temperature of the battery; and i.t is the battery discharge capacity (A.h unit).

In this study, temperature refers to the temperature of the seawater that allows the battery to operate, with a range of $-10^{\circ} \mathrm{C}$ to $50^{\circ} \mathrm{C}$. Operation beyond the testing range and the manufacturing design can significantly lower battery performance.

\section{Constant potential ( $E_{0}$, Volt unit)}

The constant potential was the value when on completed of battery discharge The calculation of $E_{0}$ follows Equation 9:

$$
E_{0}=V_{f u l l}+K_{d v}+R \cdot i-A
$$

6. Battery dynamic potential ( $V_{\text {batt }}$, Volt unit)

The dynamic potential of the battery was that under the conditions of the dynamic parameters that changed with time. The corresponding battery discharge equation was represented in Equation 2, which is Shepherd's modification equation to calculate $V_{\text {batt }}$.

Due to the effect of battery degradation, for example on the polarization phenomenon of the battery potential, the battery was limited by operating conditions with the linear zone of the nominal discharge curve. This curve was estimated between the minimum SOC ( $\left.\mathrm{SOC}_{\min }\right)$ to the maximum SOC $\left(\mathrm{SOC}_{\max }\right)$ of the maximum capacity of each battery cell. The battery output potential was updated at each stage of time using the SOC equation, estimated with Equation 10:

$$
\operatorname{SOC}(t)=\operatorname{SOC}(t-1)+\frac{i(t) * \Delta t}{Q}
$$

where $Q$ is expressed in units of A.h, and where $\Delta t$ is the time difference between $t-1$ and $t$. The battery discharge behavior pattern was updated to the required capacity limit $Q \leq Q_{\min }$, where $Q_{\min }$ was the minimum battery capacity allowed (Chang, 2013). Figure 4 shows a flow chart to determine the dynamic behavior pattern of the battery; this was used to simplify the battery 
discharge modeling steps. At each iteration during the dynamic battery model simulation process, the effect of internal resistance was incorporated into the regression model.

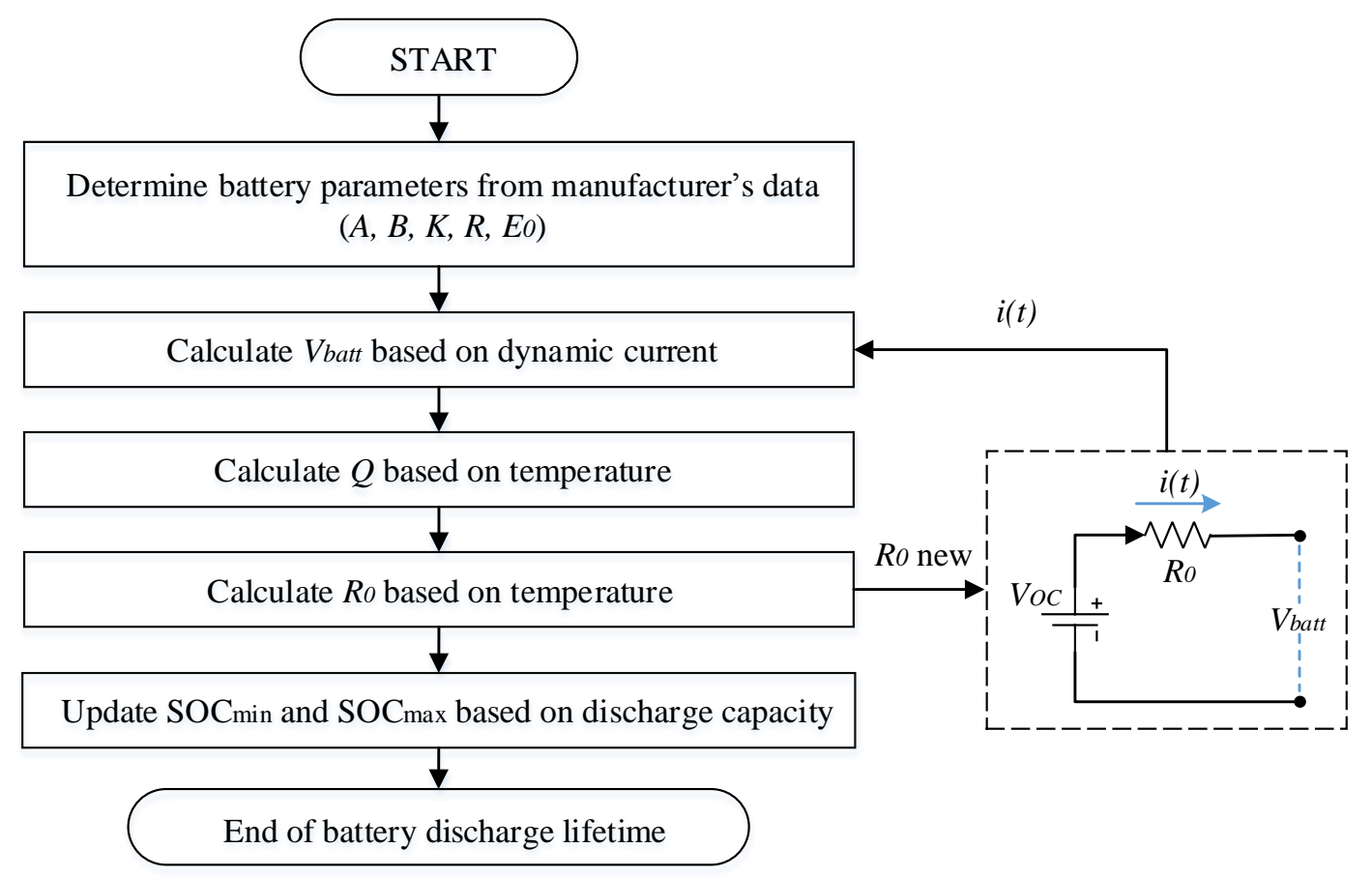

Figure 4 Algorithm for battery discharge simulation modeling

\section{RESULTS AND DISCUSSION}

\subsection{Discharge Phenomenon of a Magnesium Battery Activated by Seawater}

A representation scheme of the discharge phenomenon of the magnesium battery activated by seawater is presented in Figures $5 \mathrm{a}$ and $5 \mathrm{~b}$. The discharge curve for magnesium battery activated by seawater with variations of discharge load current is shown in Figure 6. The magnesium anode discharge performance phenomenon can be explained by the increasing level of $\mathrm{Mg}$ oxidized to $\mathrm{Mg}^{2+}$ during the discharge process. The magnesium anode is oxidized, while a reduction reaction occurs at the cathode. Electrolyte is used as the ion transfer medium between the anode and cathode in a cell. If the anode and cathode are connected to a conductor, the flow of electrons starts from the anode (negative electrode) with high electron density, to the positive electrode with low electron density. The magnesium anode release electrons (oxidized), and the carbon cathode receives the electrons at the same time. The electrons flow from the negative to positive electrode outside the circuit, so that electricity can be formed. The anion (negative ion of $\mathrm{Cl}^{-}$) diffuses into the negative electrode and the cation (positive ion of $\mathrm{Mg}^{2+}$ ) diffuses into the positive electrode in the electrolyte. The electrical circuit stops operating if there is no return movement of the ion, so no current is formed again.

There are two types of reaction in magnesium batteries activated by sea water, the main reaction and side reactions. These are the main reactions that occur during the discharge process:

Anode $\quad: \mathrm{Mg} \rightarrow \mathrm{Mg}^{2+}+2 \mathrm{e}^{-}$

Cathode $\quad: 2 \mathrm{NaCl}+2 \mathrm{e}^{-} \rightarrow 2 \mathrm{Na}^{+}+2 \mathrm{Cl}^{-}$

Total reaction $: \mathrm{Mg}+2 \mathrm{NaCl} \rightarrow \mathrm{MgCl}_{2}+2 \mathrm{Na}^{+}$

In the main reaction magnesium chloride is formed, which is the desired reaction during the battery discharge process. 
The side reactions that occur during the discharge process as follows:

Anode $\quad: \mathrm{Mg} \rightarrow \mathrm{Mg}^{2+}+2 \mathrm{e}^{-}$

Cathode $\quad: 2 \mathrm{H}_{2} \mathrm{O}+2 \mathrm{e}^{-} \rightarrow \mathrm{H}_{2}+2 \mathrm{OH}^{-}$

Total reaction : $\mathrm{Mg}+2 \mathrm{H}_{2} \mathrm{O} \rightarrow \mathrm{Mg}(\mathrm{OH})_{2}+\mathrm{H}_{2}$

The side reactions that occur result in the formation of magnesium hydroxide, which has low conductivity properties (Yu et al., 2011; Zhao et al., 2011; Yu et al., 2012; Wang et al., 2012; Chen et al., 2013). During the reaction process of magnesium batteries that are activated by sea water, hydrogen is formed on the cathode, creating a pumping action that helps clean the magnesium hydroxide, which is not soluble in the battery system. The magnesium hydroxide formed on the side reactions on the electrolyte allows the filling of the space between the electrodes. This may prevent the electrolyte from direct contact with the electrode, preventing the flow of ions, and causing a malfunction of the battery, also called premature cells (Koontz \& Lucero, 2002). The potential standard of magnesium is $2.370 \mathrm{~V}$ vs. SHE theoretically. However, the potential value of magnesium battery discharges activated by sea water ranges from $1.49 \mathrm{~V}$ to $1.30 \mathrm{~V}$, according to the experimental data in Figure 6. The formation of magnesium hydroxide can weaken the battery discharge performance of seawater, as it will lower the conductivity of the electrolyte. However, seawater batteries are widely applied with open systems, so the influence of magnesium hydroxide can be minimized because of the circulation of seawater. In other words, the magnesium hydroxide formed will also circulate into the environment. This is beneficial, because the seawater battery can maintain its discharge performance.

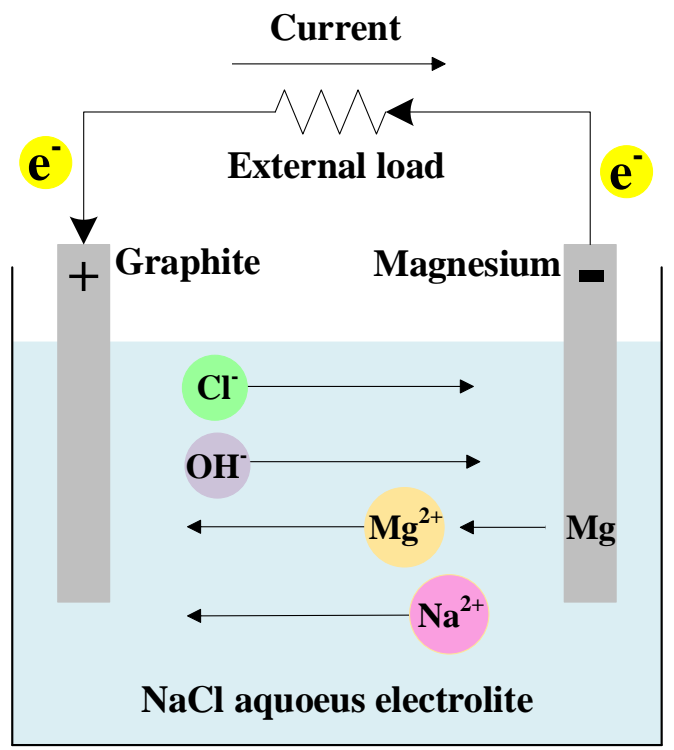

(a)

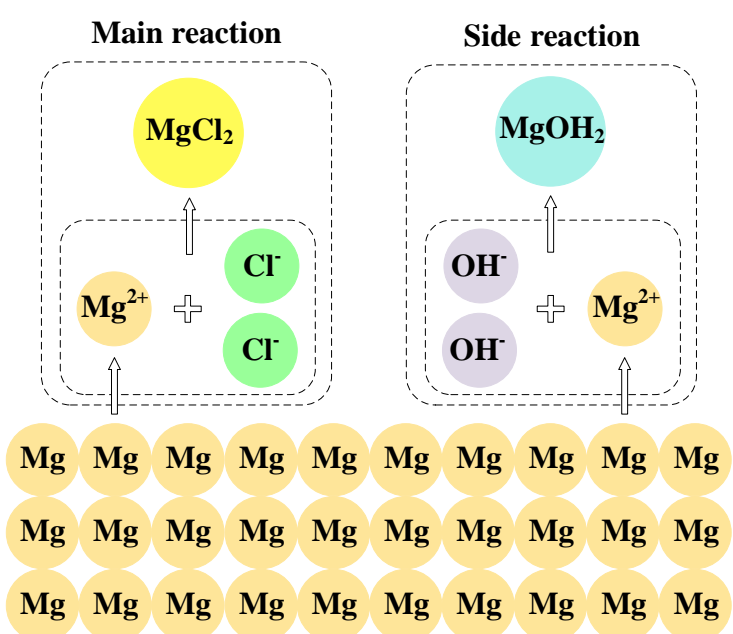

(b)

Figure 5 (a) Schematic representation of discharge phenomenon of magnesium battery activated by seawater; (b) discharge reaction phenomena

\subsection{Retrieval of Battery Discharge Manufacturing Data}

The calculation of the modeling parameters for potential and discharge current is related to the manufacturing data obtained from the battery discharge curve. The parameters in figure 6 are selected based on the ideal curve of figure 1 . The battery discharge uses three different current loads to determine the performance of the magnesium batteries activated by seawater at low, medium and high constant current loads. The low discharge current load used is $0.01 \mathrm{C}$; the medium current load is $0.05 \mathrm{C}$; and the high discharge current load used is $0.1 \mathrm{C}$. Different current loads of course impact on the lifetime of the battery. Battery lifetime is longer for low 
load currents than high load ones, because the amount of oxidized magnesium at low currents is less than that at high currents. The higher current is identified with the increasing number of electrons released due to the oxidation of $\mathrm{Mg}$ to $\mathrm{Mg}^{2+}$ (Zhao et al., 2011).

The manufacturing data is taken from one of the battery discharge curves; that is, at $0.1 \mathrm{C}$ current load. This is because the curve model is closest to the ideal discharge graph model, as shown in Figure 1. The battery discharge parameters at $0.1 \mathrm{C}$ current load are presented in Table 1.

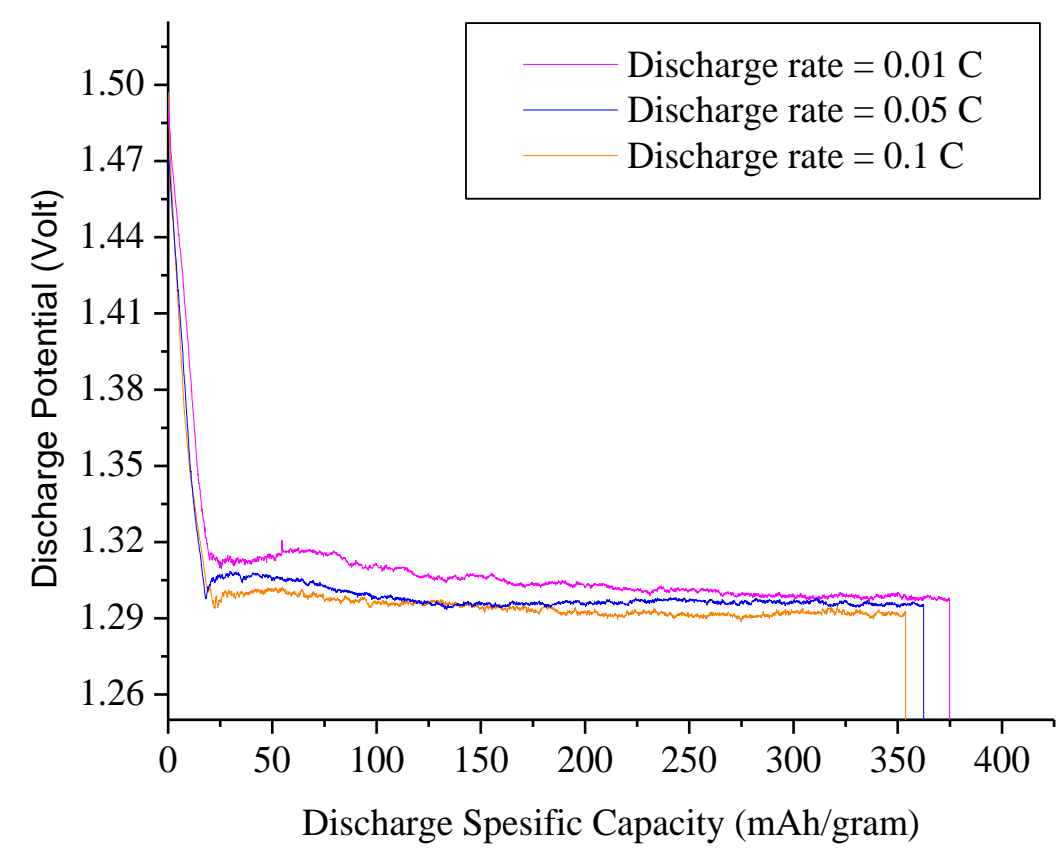

Figure 6 Discharge curves for magnesium batteries with varying current loads

Table 1 Battery discharge parameters based on manufacturing data

\begin{tabular}{ccc}
\hline Parameter & Unit & Value \\
\hline$Q_{\text {full }}$ & $\mathrm{mAh} /$ gram & 353.854 \\
$V_{\text {full }}$ & Volt & 1.497 \\
$Q_{\text {exp }}$ & $\mathrm{mAh} / \mathrm{gram}$ & 20 \\
$V_{\text {exp }}$ & Volt & 1.302 \\
$Q_{\text {nom }}$ & $\mathrm{mAh} / \mathrm{gram}$ & 353.75 \\
$V_{\text {nom }}$ & Volt & 1.292 \\
$\mathrm{SOC}_{\min }$ & $\%$ & 1 \\
$\mathrm{SOC}_{\max }$ & $\%$ & 94 \\
\hline
\end{tabular}

\subsection{Model Validation}

Battery discharge manufacturing data was used to validate the accuracy of the battery model. The curves were compared to the simulation results and the manufacturing data are shown in Figure 7. The parameters obtained from the simulation results are presented in Table 2. In Figure 6 it can be seen that there is a convergence between the battery discharge manufacturing data and the simulated discharge data, while in Table 2 it can be seen that the $K_{d v}$ value is very small. This indicates that the difference between the exponential and nominal parameters is not very significant. The same pattern can also be seen in the battery discharge manufacturing data. Discharge patterns such as these are indeed desired for the battery, because during battery to used can maintain discharge performance. The smaller the value of the difference between the 
exponential and nominal parameters, the better the discharge performance of the battery (Zhao et al., 2011).

Determination of $\mathrm{SOC}_{\min }$ and $\mathrm{SOC}_{\max }$ values is important. The $\mathrm{SOC}$ limit present in the battery capacity range is allowed to operate. There is a difference between the $\mathrm{SOC}_{\min }$ and $\mathrm{SOC}_{\max }$ values in the battery discharge manufacturing data $\left(\mathrm{SOC}_{\min }=1 \%, \mathrm{SOC}_{\max }=94 \%\right)$ and the simulated discharge data $\left(\mathrm{SOC}_{\min }=5 \%, \mathrm{SOC}_{\max }=93 \%\right) . \mathrm{SOC}_{\min }$ and $\mathrm{SOC}_{\max }$ limit values in the simulated data can be used as the safety value limits for battery operation. $\mathrm{SOC}_{\min }$ is used as a battery usage indicator value so that its performance does not decrease dramatically before it is completely discharged, while the $\mathrm{SOC}_{\max }$ value of the secondary battery is useful for establishing at what limit value the battery actually operates at a relatively stable value. Convergence is also seen between the discharge current from the manufacturing data and the simulated data, although there is little deviation value (Figure 7c). The deviation of this value is not considered significant because of its low value of $0.0054 \mathrm{~mA}$. The SOC value will decrease along with battery discharge (Figure $7 \mathrm{~d}$ ). The manufacturing data and simulation result data show almost perfect convergence in the linear pattern between them. The percentage of simulated data error compared to manufacturing data is $0.85 \%$.

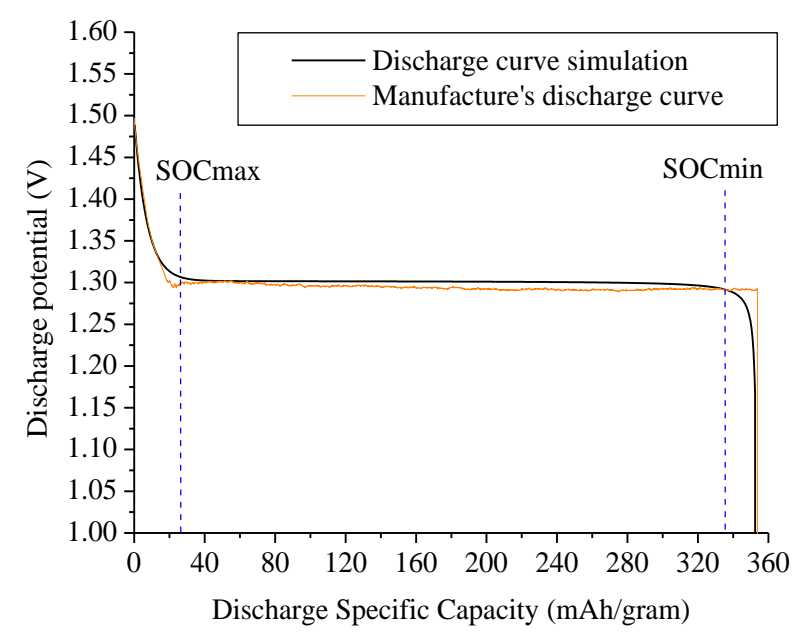

(a)

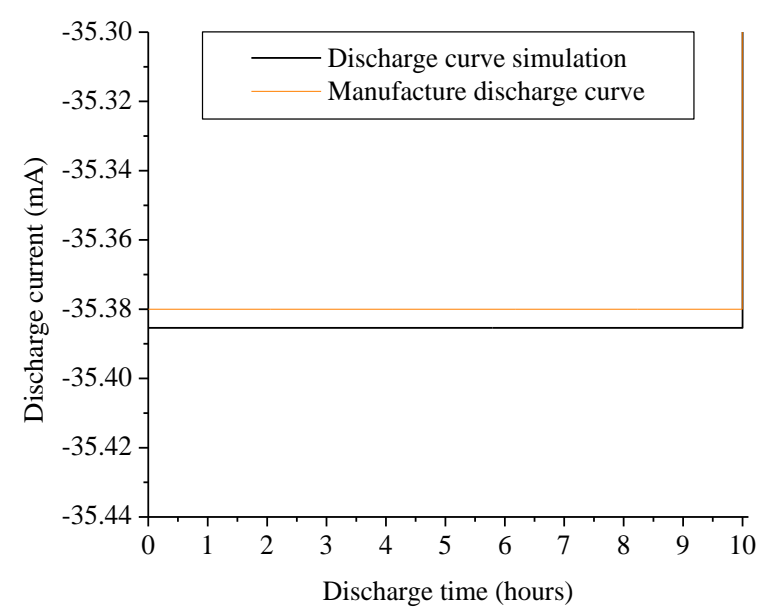

(c)

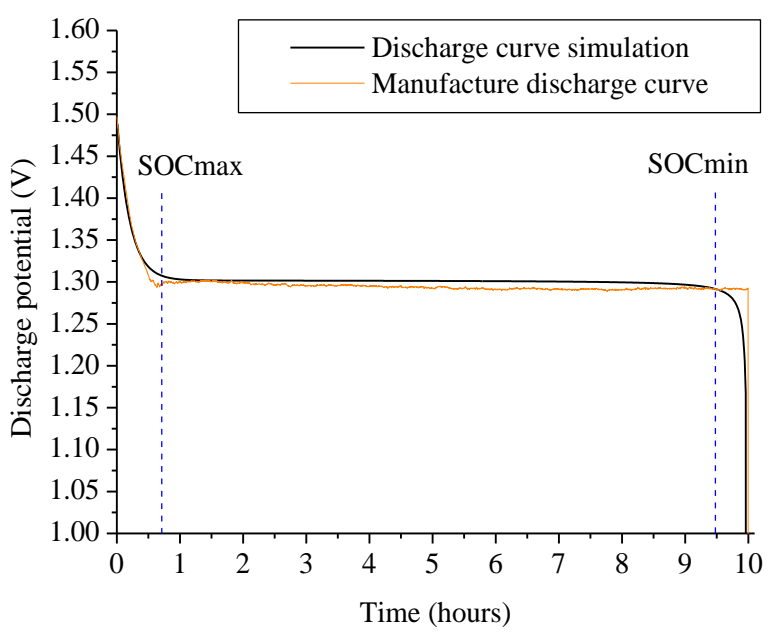

(b)

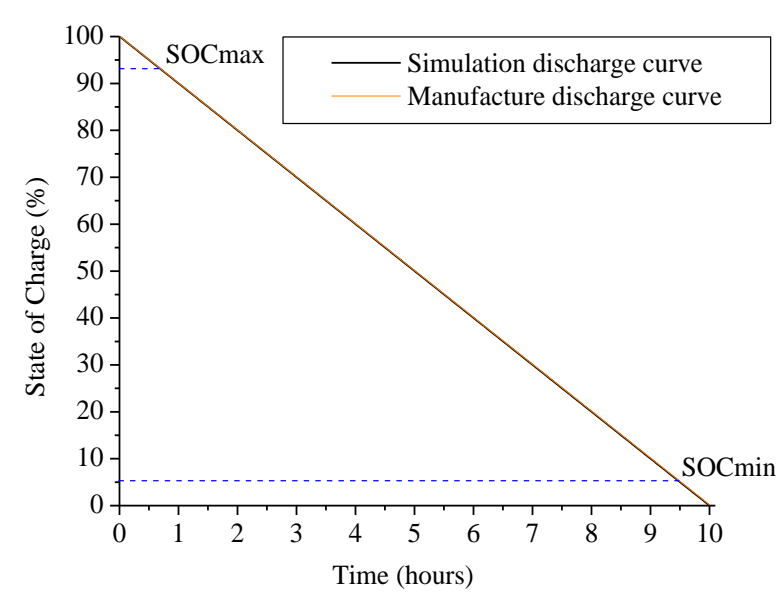

(d)

Figure 7 Discharge modeling curve plotted against battery manufacturing data at $0.1 \mathrm{C}$ discharge rate: (a) $Q$ vs $V_{\text {batt }}$; (b) $t$ vs $V_{\text {batt }}$; (c) $t$ vs $I$; (d) $t$ vs SOC 
Table 2 Battery discharge parameters obtained from the simulation data

\begin{tabular}{lcc}
\hline Parameter & Unit & Value \\
\hline$E_{0}$ & Volt & 1.303 \\
$R$ & $\Omega$ & 0.012 \\
$K_{d r}$ & $\Omega$ & 0.01 \\
$K_{d v}$ & Volt/A.h & $5.794 \times 10^{-4}$ \\
$A$ & Volt & 0.195 \\
$B$ & $(\text { A.h })^{-1}$ & 140 \\
SOC $_{\min }$ & $\%$ & 5 \\
SOC $_{\max }$ & $\%$ & 93 \\
\hline
\end{tabular}

\section{CONCLUSION}

Battery discharge potential decreases from $\pm 1.49 \mathrm{~V}$ to $\pm 1.30 \mathrm{~V}$, and is is stable after $\pm 1.30 \mathrm{~V}$ to the $\mathrm{SOC}_{\min }$ potential value $( \pm 1.29 \mathrm{~V})$. Modeling the discharge using the Shepherd modification model combined with the $R_{\text {int }}$ equivalent circuit model compared show that the manufacturing data is convergent with the modeling parameters $E_{0}=1.303 \mathrm{~V} ; R=0.012 \Omega ; K_{d r}=0.01 \Omega ; K_{d v}$ $=5.794 \times 10^{-4}$ V/A.h; $A=0.195 \mathrm{~V}$; and $\mathrm{B}=140(\mathrm{Ah})^{-1}$. The $\mathrm{SOC}_{\min }$ value of $5 \%$ was used as the minimum allowed safety limit so that battery performance did not fall drastically during operation. The $\mathrm{SOC}_{\max }$ value of $93 \%$ was used as the maximum allowed safety limit to allow the battery to operate steadily. The percentage of simulated data error compared to manufacturing data was $0.85 \%$.

\section{ACKNOWLEDGEMENT}

The author would like to thank the Department of Chemical Engineering, Faculty of Engineering, Universitas Brawijaya for facilitating this modeling-based research. The author hope the research results obtained from the modeling can be used as a reference for further research on magnesium batteries activated by seawater.

\section{REFERENCES}

Benabdelaziz, K., Maaroufi, M., 2017. Battery Dynamic Energy Model for Use in Electric Vehicle Simulation. International Journal of Hydrogen Energy, Volume 42(30), pp. 19496-19503

Bard, A.J., Faulkner, L.R., 2001. Electrochemical Method, John Wiley \& Sons inc., New York, United States of America

Chang, W.-Y., 2013. The State of Charge Estimating Methods for Battery: A Review, ISRN Applied Mathematics, Volume 2013, pp. 1-7

Chen, B., Wang, R., Peng, C., Feng, Y., Wang, N., 2013. Influence of Al-Mn Master Alloys on Microstructures and Electrochemical Properties of Mg-Al-Pb-Mn Alloys. Transaction of Nonferrous Metals Society of China, Volume 24(2), pp. 423-430

Durr, M., Cruden, A., Gair, S., McDonald J.R., 2006. Dynamic Model of a Lead Acid Battery For Use in a Domestic Fuel Cell System. Journal of Power Sources, Volume 161(2), pp. $1400-1411$

Guo, B., Wu, J., Qun, J., Han, Q., 2017. The Lithium-ion Battery Standby Power of Wind Turbine Pitch System, Energy Procedia, Volume 105, pp. 3539-3544

He, H., Xiong, R., Guo, H., Li, S., 2012. Comparison Study on the Battery Models Used for the Energy Management of Batteries in Electric Vehicles. Energy Conversion and Management, Volume 64, pp. 113-121

Koontz, R.F., Lucero, R.D., 2002. Magnesium Water Activated Batteries, McGraw-Hill, United State of America 
Kuhn, E., Forgez, C., Lagonotte, P., Friedrich, G., 2006. Modelling Ni-mH Battery Using Cauer and Foster Structures. Journal of Power Sources, Volume 158(2), pp. 1490-1497

Li, S., Ke, B., 2011. Study of Battery Modeling using Mathematical and Circuit Oriented Approaches. IEEE Power and Energy Society General Meeting, pp. 1-8

Mauracher, P., Karden, E., 1997. Dynamic Modelling of Lead/acid Batteries Using Impedance Spectroscopy for Parameter Identification. Journal of Power Sources, Volume 67(1-2), pp. 69-84

Rao, R., Vrudhula, S., Rakhmatov, D.N., 2003. Battery Modeling for Energy-Aware System Design. Computer, Volume 36(12), pp. 77-87

Supriyono, Wulaningfitri, L.P.M.I., Pradana, J.C., Feliana, I., Putri, A.N., 2017. Discharge Performance Characteristics of Anodized Magnesium Activated by Seawater (Karakteristik Performa Discharge Anoda Magnesium Teranodisasi yang Teraktivasi oleh Air Laut). Jurnal Rekayasa Bahan Alam dan Energi Berkelanjutan. Volume 1(2), pp. 56-62 (in Bahasa)

Shepherd, C., M., 1965. Design of Primary and Secondary Cells - Part 2. An Equation Describing Battery Discharge. Journal of Electrochemical Society, Volume 112, pp. 657664

Tremblay, O., Dessaint, L.A., 2009. Experimental Validation of a Battery Dynamic Model for EV Applications. World Electric Vehicle Journal, Volume 3, pp. 289-298

Tremblay, O., Dessaint, L.A., Dekkiche, A.I., 2007. A Generic Battery Model for the Dynamic Simulation of Hybrid Electric Vehicles. IEEE Vehicle Power and Propulsion Conference, pp. 284-289

Wang, N., Wang, R., Peng, C., Feng Y., Chen, B., 2012. Effect of Hot Rolling and Subsequent Annealing on Electrochemical Discharge Behavior of AP65 Magnesium Alloy as Anode for Seawater Activated Battery. Corrosion Science, Volume 64, pp. 17-27

Yu, K., Tan, X., Hu, Y., Chen, F., Li, S., 2011. Microstructure Effects on the Electrochemical Corrosion Properties of Mg-4.1\% Ga-2.2\% Hg Alloy as the Anode for Seawater Activated Batteries. Corrosion Science, Volume 53, pp. 2035-2040

Yu, K., Huang, Q., Zhao, J., Dai, Y., 2012. Electrochemical Properties of Magnesium Alloy Anodes Discharged in Seawater. Transaction of Nonferrous Metals Society of China, Volume 22(9), pp. 2184-2190

Zhao, C., Dong, S., Li, F., Song, Y., 2015. Optimal Home Energy Management System with Mixed Types of Loads. CSEE Journal of Power and Energy Systems, Volume 1(4), pp. 29-37

Zhao, J., Yu, K., Hu, Y., Li, S., Tan, X., Chen, F., Yu, Z., 2011. Discharge Behavior of Mg-4 wt $\% \mathrm{Ga}-2 \mathrm{wt} \% \mathrm{Hg}$ Alloy as Anode for Seawater Activated Battery. Electrochimica Acta, Volume 56(24), pp. 8224-8231 